\title{
Vides exemplars. Terciàries carmelitanes a E1 Carmelo Esmaltado de Roque Alberto Faci (1743)
}

\section{Exemplary lives. The carmelites women of third order in El carmelo esmaltado by Roque Alberto Faci (1743)}

\author{
Cristina Gimeno-Maldonado \\ cristina.gimma@gmail.com
}

Universitat Autònoma de Barcelona

\begin{abstract}
Resum: Carmelo Esmaltado con tantas brillantes estrelles, cuantas flores terceras, fecundas de frutos de virtud y religión, cultivó y fijo en el cielo de la Santa Iglesia la venerable Orden Tercera de Nuestra Señora del Carmen, és el títol de l'obra que el carmelita aragonès Roque Alberto Faci (1684-1744) va publicar el 1743. El llibre és un tractat per als membres de la tercera ordre del Carmel en què trobem diverses biografies de terciàries carmelites. El que pretendrem a partir de l'anàlisi de la obra i les biografies, és fixar el paper de les terciàries al món carmelita. Per això, analitzarem l'objectiu de l'autor tenint en compte la religiositat i espiritualitat del segle XVIII i la projecció de la Il lustració.
\end{abstract}

Paraules clau: Carmel, Dones, Religiositat, Seglar, Terciaris

\begin{abstract}
Carmelo Esmaltado con tantas brillantes estrelles, cuantas flores terceras, fecundas de frutos de virtud y religión, cultivó y fijo en el cielo de la Santa Iglesia la venerable Orden Tercera de Nuestra Señora del Carmen, is the title of the book wrote by the aragonian carmelite Roque Alberto Faci (1684-1744) published in 1743. The issue is a treaty for the members of the Third Order of Carmel where we can find several biographies of the carmelites woman of third order. What we pretend by analyzing their work and biography is to set the role of the woman of the third order in the world Carmel. For that, we aimed copyright considering religiosity and spirituality of the eighteenth century and the projection of the Enlightenment.
\end{abstract}

Keywords: Carmel, Woman, Religiosity, Secular, Tertiary 
Cristina Gimeno-Maldonado. Vides exemplars. Terciàries carmelitanes a El Carmelo Esmaltado de Roque Alberto Faci (1743)

En un apropament a la religiositat i espiritualitat del segle XVIII és necessari tenir present la història social del territori a analitzar des de concepcions diferents. Breument repassarem certs factors amb la finalitat de situar-nos en el context sociocultural del moment, centrant-nos al marc geogràfic hispànic. En primer lloc, començarem remarcant les diferències amb els preceptes religiosos que s'establiren durant els segles XVI i el XVII, on trobem una religiositat basada en els paràmetres que dictà el Concili de Trento (1545-1563). El sistema tridentí va desenvolupar una tasca important de control social, a través de la qual tots els estaments socials trobaren el seu lloc on consagrar-se. En concordança, el catolicisme sorgit del Concili va actuar de tal forma que no només disciplinava i inspeccionava, sinó que també ideava estratègies per mobilitzar i reconduir la religiositat popular (Prosperi 2008). Aquesta cultura de la confessionalització però, va perdre força amb l'entrada del segle XVIII. L'estil de la contrareforma patí un descens quant al fervor religiós, sobretot a causa del desinterès que les elits començaren a sentir (Po-Chi Hsia 2010: 255-273).

En segon lloc, cal tenir en compte les diferències territorials cada vegada més grans. A França es va donar pas a les directrius llibertines de Lluís XV; a Alemanya, prínceps i nobles acudien a l'opera en lloc del teatre; i preferències similars esdevingueren als Països Baixos. Aquestes tendències transgressores no es van establir de forma universal, i encara que el catolicisme espanyol no va perdre força en temps dels borbons, es va percebre una subtil falta de rellevància social en comparació amb els dos segles anteriors. Cal destacar un important descens de famílies treballant per al Sant Ofici i que aquestes, a l'últim segle de la seva existència, procedien de capes socials molt més baixes. Aquest fenomen, sobretot es devé a problemes teològics i eclesiològics, que encara que tan sols afectar-ne a les elits, empitjoraven els problemes existents entre l'Església i l'Estat (Martínez Albiach 1969). De fet, els reis de la casa de Borbó es van mostra progressivament més bel ligerants a favor del regalisme i de la reforma eclesiàstica (De la Hera Pérez-Cuesta 2014: 645-659).

En tercer lloc, i centrant-nos en l'evolució de la Il lustració Catòlica a la Península, observem l'abandonament de pràctiques pomposes, d'evident herència barroca, que ja no encaixaven en una època en què la filosofia, la ciència i el racionalisme començaven a desenvolupar una nova manera de viure l'espiritualitat. Per tota Europa es propagaren les crítiques del novators, catòlics il lustrats que censuraven les deficiències d'aquella espiritualitat i que van iniciar una campanya a favor d'una religiositat més sincera i interior. Espanya no fou cap excepció. Personatges com Feijoo (1676-1765) amb el seu Discurso sobre les glorias de España, Campomanes (1723-1802), Jovellanos (1744-1811), Mayans (1699-1781) i el seu Orador Cristiano, o Capmany (1742-1813), entre altres, van reflectir antipatia pel sermons barrocs i les altres artificiositats (Raab 1978: 221-770).

Per tant, quant a la religiositat, trobem aquesta pugna de sensibilitats que en cada país va ser viscuda d'una manera concreta. Malgrat això, no podem considerar que a l'Espanya del XVIII hi hagués un sentiment anticlerical perquè es pot veure la vinculació religiosa de destacats il lustrats que militaren al camp de les llums catòliques. A més, pel que fa al gran nucli poblacional, el centre de 
Cristina Gimeno-Maldonado. Vides exemplars. Terciàries carmelitanes a El Carmelo Esmaltado de Roque Alberto Faci (1743)

la vida religiosa va continuar sent la missa dominical. Però, podem considerar que el fervor religiós no va continuar sent el mateix, ja que els sermons de l'època van adoptar un caire diferent. Es van esforçar per assenyalar i lloar mèrits dels segles anteriors, factor que porta a pensar que ja no es complien tots el preceptes tradicionals de l’Evangeli a la perfecció (Méstre Sanchís 1979: 586-605).

\section{L'espiritualitat del laic al segle XVIII}

Establerts els paràmetres més generales, cal entendre a la majoria del poble, gairebé petrificat a la tradició, segons el discurs il lustrat. Abans d'avançar, cal fer referència a les paraules d'Eulogio de la Vega del Carmen (1969: 281) i la seva caracterització de l’època: «Entre el barroco y la ilustración no existe isocronía ni riguroso progreso cronológico. Por convenir buena parte de su existencia histórica, no pueden servir como punto de referencia al describir la evolución de la literatura espiritual». Per tant, cal tenir en compte les variants, alternances i interferències d'ambdós fenòmens culturals perquè ens mourem entre dos corrents culturals que van conviure, però no per això arribaren a cap grau de compenetració.

Durant aquesta confluència d'expressions el clergat es debaté entre dos posicions. Per una banda, va continuar lluitant per difondre l'esperit de la contrareforma; per l'altre, sota el segell de la Il lustració, hi van haver implicacions en algunes reformés eclesiàstiques arran del reformisme borbònic. Aquesta batalla al si de l'elit religiosa provocà una pèrdua important del seu influx tan polític com social. Des del punt de vista popular, el clergat va ser motiu de crítica, especialment els monjos, que van ser considerats els culpables de certa relaxació religiosa, encara que aquests fenomen no afectà a tots el religiosos en la mateixa mesura. Els frares van continuar gaudint del reconeixement popular perquè eren part de les vicissituds socials (Martínez Albiach 1969: 392440). A més, la pietat popular, vehiculada a través de devocions culturals com processons, festes o qualsevol expressió que permetés una manifestació religiosa era ben rebuda pels espanyols, que sortien al carrer com cristians fidels (Méstre Sanchís 1979: 586-605). Aquestes manifestacions exteriors de pietat eren possibles gràcies a les confraries, associacions formades per religiosos i laics que constituien una base estructural organitzada. L'esperit d'associació servia d'estímul per la pràctica de bones obres, la pervivència de la fe i per mantenir viu el sentiment religiós. Aguilar Piñal (1976: 228-229) assenyala el contrast amb els segles anteriors considerant el XVIII com un segle que va s'encamina cap a la secularització, però que alhora estava ple de noves confraries en molts punts d'Espanya.

Per tant, pel conjunt de la població, l'homilia dominical i els sermons de festes, entre altres pràctiques, continuaven tenint una importància social i política important. Cal destacar que, entre els espanyols del segle XVIII, que estaven majoritàriament mancats de llibres, premsa o altres mitjans, el sermó constituia l'única font de contacte amb el món religiós, cultural o polític. Per això cal matisar la idea de la descristanizació, encara que en altres escenaris historiogràfics, com el francès o l'italià, s'hagi insistit en la disminució progressiva de pràctiques pies. Al cas hispà comprovem que no va ser així 
Cristina Gimeno-Maldonado. Vides exemplars. Terciàries carmelitanes a El Carmelo Esmaltado de Roque Alberto Faci (1743)

(Antón Solé 1994), l'assistència a missa continuava tenint un important arrelament popular, així com resar el rosari, la devoció a la Mare de Déu i tantes altres pràctiques.

Per altre banda, quan analitzem el sentiment popular, cal tenir en compte que l'església havia fomentat sempre la pietat personal i particular del fidels, no només com una prolongació del culte oficial. L'associacionisme espontani i lliure entre els fidels i els eclesiàstics va ser present contínuament a la història de l'església. Això respon a un moviment espiritual que busca la seguretat del grup. Per això l'Església el va controlar més que reprimir, sempre i quan no suposés un moviment contestatari o una organització paral lela amb pretensions heterodoxes. De fet, hi hagueren èpoques en què la jerarquia eclesiàstica va recórrer a les germandats i confraries per tal de corregir la disminució del fervor religiós i fomentar el culte, la catequesis i la caritat, però exigint la corresponent reglamentació, aprovació i control (Méstre Sanchís 1979: 586-613). En relació amb aquests actius hi trobem la branca terciària de les ordres religioses. Laics, que en resposta a la crida particular de Déu, van prometre viure la vida de l'Evangeli mantenint les seves famílies i feines. ${ }^{1}$ És a dir, era una formació de fidels que, sota la guia i segons l'esperit de cada ordre, es comprometien a perseguir la perfecció cristiana com a la vida secular. La finalitat dels membres era tendir cap a la perfecció cristiana de forma privada i individual. Per tant, les terceres ordres comportaren innovacions profundes en el concepte i realització de la vida religiosa. Aquestes ramificacions religioses serviren per ampliar les possibilitats religioses d'homés i dones que participaren en diferents activitats, però també oferint certa forma de sociabilitat per laics (Torremocha Hernández 2015: 181-210).

Aquest fenomen ens condueix a pensar que al segle XVIII la passió religiosa amb les seves devocions pertinents, ja no era exaltada pels arquetips que d'èxit de segles anteriors, sinó que es visqué amb més entusiasme als carrers. En certa manera, la tendència associativa popular, que no era nova ni diferent, va adquirir més protagonisme, convertint el laic en un component més actiu de l'Església, en comparació amb moments històrics anteriors. Per tant, la vida religiosa ja no estava tancada als monestirs i convents, sinó que hi havia irradiacions vitals a favor del laics. Això obre un panobranca ampli de persónes de procedències molt diverses, que en mésura gradual i no sempre fàcilment definible, se vincularen amb la vida monàstica, però romanent al món.

\subsection{La construcció d'una identitat exemplar: dones a l'Església}

Cal obrir un parèntesis dins d'aquesta dimensió popular per tal d'analitzar el paper de les dones, que tot i trobar-se en el mateix territori, és necessari incorporar elements singulars, com ja han fet evident diferents investigacions. ${ }^{2}$

1 Quant a l'exactitud històrica i jurídica, hem de fixar-nos en els documents pontificis que aprovaren cada ordre tercera. Entre els carmelites, la denominació terciari apareix cap a mitjan segle XVI amb alguna excepció situada a la segona meitat del 1400. Però la nomenclatura pròpia es verificà per Nicolau V, el 7 d'octubre de 1452, a la butlla Cum nulla. En ella, el pontífex no parla de quelcom que s'hagi d' instaurar, sinó d'un estat de coses ja existents.

2 Recuperar la memòria femenina hauria de traduir-se en fomentar una parcel la a la historiografia dedicada a la dona assumint la història oficial, masculina per defecte. S'han obert diversos debats sobre el com abordar aquests

SCRIPTA, Revista internacional de literatura i cultura medieval i moderna, núm. 8 / desembre 2016 / pp. 241-256 ISSN: 2340-4841 · doi:10.7203/SCRIPTA.8.9297 
Cristina Gimeno-Maldonado. Vides exemplars. Terciàries carmelitanes a El Carmelo Esmaltado de Roque Alberto Faci (1743)

Durant els segles XVI, XVII i XVIII trobem que els valors socials dominants es basaren en conceptes com l'honradesa i la honestedat familiar, que residien en gran part en una determinada visió de la virtut femenina. Les conductes moralment acceptades i èticament bones eren aquelles que respectaven aquests valors, ja que no posaven en perill la societat estamental que regia. Contràriament, qualsevol acció o conducta que violentés aquests principis queia a l'òrbita de la transgressió. Durant aquesta època es va accelerar la construcció d'una identitat femenina que té com a trets fonamentals la subordinació a allò masculí, la desigualtat legal respecte l'home, els límits de l'exercici de la sexualitat; elements que remetien a aquesta idea de virtut. Els models de dones que s'imposaren des del poder tenien intencions clarament moralitzant i didàctiques. Amb aquesta finalitat es van fer servir diferents instruments de transmissió ideològica: l'art, la literatura, juntament amb altres mètodes d'imposició ideològica que posseïssin qualitats propagandístiques, complementaren la funció moralitzant social alhora que es reproduien mitjançant l'adoctrinament de determinats patrons sobre la dona (Cuartero Arina 2013: 65).

A extramurs, trobem a una majoria de dones piadoses que no acabaren professant, ja fos perquè rebutjaren o evitaren el convent, o perquè no pogueren accedir-hi per condicionaments familiars, socials o econòmics. No hem d'oblidar que les places als convents femenins eren limitades. Fins i tot per qui podia assumir el cost de la dot, la demanda superava l'oferta. Es aquí on trobem a beates, particulars o col lectius de dones que buscaren solucions i sortides informals (Atienza 2013: 89-105). Les dones de l'època van haver d'enfrontar-se a problemes d'ubicació social. Els moralistes del període aviat se n'ocuparen en els seus escrits, especialment de les vídues, per ser dones que quedaven de cop sense un home que les tutelés. Lluís Vives (1492-1540) recomanava que estiguessin tancades, i si sortien de casa, ho fessin cobertes i només per anar a llocs poc transitats. Alonso de Andrade (1590-1672) afirmava que quan es moria el marit, s'havia de tractar a la dona com si hagués mort amb ell (Vigil 1986: 195).

Dins d'aquesta producció moralista trobem aquella literatura devota i espiritual que oferí una infinitat d'escrits hagiogràfics i vides. ${ }^{3}$ Actualment l'interès per aquest gènere no radica en la literalitat dels episodis que recollien, ja que el seu valor com a referència històrica resulta qüestionable. Però sí que cal analitzar dita literatura en funció de la utilitat, ja que el règim de la veritat quedava supeditat per la seva funció didàctica. És a dir, hem de fixar-nos en el valor que posseïen aquests escrits a l'hora d'articular un discurs de clares intencions edificants (Alabrús Iglesias, García Cárcel 2015: 19-50).

Malgrat que en el segle XVIII aquests tipus de relat no tingués el mateix èxit que en èpoques anteriors, les vides exemplars seguiren sent útils per la guia de consciències i orientació de conductes femenines. De fet, és en aquest segle quan els homes més van escriure sobre les dones i més persuasius es mostraren intentant canalitzar la sensibilitat femenina (López-Cordón Cortezo 2015:

estudis. Sense aprofundir en cap, evitaré el discurs sobre lo femení com un annex a la història general, però si generant posicions més matisades, ja que, en tota societat, les relacions entre els sexes s'han caracteritzat per tenir un caràcter asimètric $i$ jeràrquic.

3 Entenent aquestes «vidas» com a relats biogràfics o autobiogràfics que s'escriviren amb el fi d'exemplaritzar. 
Cristina Gimeno-Maldonado. Vides exemplars. Terciàries carmelitanes a El Carmelo Esmaltado de Roque Alberto Faci (1743)

147-181). Per tant, cal destacar la importància d'aquestes obres quant a les funcions socioculturals, a l'hora d'influir a l'individu de manera íntima i personal, i la utilitat forjant identitats locals o de grup (Palomo 2013: 53-88).

\section{Els terciaris carmelites}

Partint de la base de que durant el segle XVIII el laic tingué un nou protagonisme a l'Església, mitjançant la seva participació a actes públics de cohesió i devoció, cal analitzar el paper del terciaris. En especial, aquells que formaren part de la tercera ordre del Carme, ja que, a banda de constituir una important branca de l'ordre, fou al segle XVIII quan aquesta va adquirir un volum numèric i un protagonisme social no viscut fins el moment (Velesco, O.Carm. 1993: 251-253).

La formació jurídica d'aquesta tercera branca la trobem a la bula Cum nulla, expedida per Nicolau V el 7 d'octubre de 1452 (Ancilli 1984: 470-473). Però, malgrat tenir constància de la seva existència amb anterioritat (Wilderink 1966), ${ }^{4}$ comencem a detectar les primeres publicacions dirigides a aquesta organització a finals del segle XVI. Parlem d'obres que orientaven als membres cap a la correcta professió de dos vots simples: castedat i obediència. Una de les primeres publicacions que intentà normativitzar el grup fou el Manual de les beatas y bermanos terceros de Diego Martínez de Coria Maldonado (Sevilla, 1592). No obstant, en aquesta obra no s'establi la distinció entre terciaris i membres de la confraria. Aquesta diferència es troba més explicita a la Regla y modo de vida de los hermanos terceros y beatas de N.S. del Carmen de Miguel de la Fuente (Toledo, 1615). Completament independent a aquest manual sorgí Tesoro espiritual de Elias Maruggi (Catania, 1624). Aquesta obra beu d'allò que va escriure Marcos de Guadalajara (Zaragoza, 1616), amb la qual en comparteix el títol. Aquests últims llibres destaquen perquè van dirigits a un públic en concret, dones solteres i vídues. Factor que porta a pensar que aquests eren els perfils més afins a la tercera ordre. Hereus d'aquesta orientació femenina trobem els Opusculum regularum et constitutionum de Straccio (Ronciglione, 1637), interessants per ser el primer intent de proporcionar una regla oficial a la tercera ordre, però per a tots els membres, sense diferències territorial. L'historiador carmelita Smet defesa que probablement fou Juan Bautista Lezana (1586-1659) l'ideòleg d'aquesta pauta genuïna (Smet O. Carm. 1991: 157-159). No en coneixem l'autor, però a grans trets resumirem que els vots exigits als terciaris, exceptuant el de pobresa, essent els mateixos que els professats per la resta de frares i monges. Aquests canons de comportament es dirigiren tant a homes com a dones, casats o solters, encara que denoten una predilecció per les dones no casades.

Quatre dècades més tard, el 1679, trobem que el general Emilio Giacomelli publicà una nova regla a la qual el seu successor, Fernando Tartaglia, afegí uns estatuts el 1679. Aquesta legislació, que

4El general Juan Soreth (1405-1471) va incorporar a les comunitats femenines de beguines donant-los hàbit i la regla del Carmel. Alhora, s'estableixen monestirs carmelites a la Bretanya francesa que varen ser fundats per la duquessa de Bretanya, Françoise d'Amboise (1427-1485).

SCRIPTA, Revista internacional de literatura i cultura medieval i moderna, núm. 8 / desembre 2016 / pp. 241-256 ISSN: 2340-4841 · doi:10.7203/SCRIPTA.8.9297 
Cristina Gimeno-Maldonado. Vides exemplars. Terciàries carmelitanes a El Carmelo Esmaltado de Roque Alberto Faci (1743)

clarifica i perfecciona la de Straccio, es va fer amb la intenció de substituir totes les altres regles anteriors i així marcar el final del que podríem considerar primer període de l'evolució jurídica de la tercera ordre carmelita. No obstant, aquests preceptes mai varen ser acceptats per la tercera ordre d'Espanya i Portugal. Els territoris peninsular van continuar seguint la regla de Straccio, malgrat una diferencia important: no s'exigia als membres fer vots, sinó només promeses o compromisos, sense més obligacions en consciència. Aquests últims preceptes varen ser els que assumiren distints tractadistes carmelites com Juan Bonet (1573-1633) o Roque Alberto Faci (1684-1744), que varen seguir l'estela de Straccio i manifestaren les seves influències a les seves obres(Smet, O. Carm. 1991: 157-159). Aquesta regla, que és la Regla de Sant Albert adaptada a la vida dels seculars, parteix de la premissa de portar una vida cristiana compromesa, segons l'esperit carmelita, en la oració i servei. Cal destacar que, malgrat que als territoris ibèrics no s'acceptessin els preceptes establerts des del generalat de l'ordre, fou en aquests territoris i els seus dominis on la tercera ordre va créixer com enlloc. Aquest auge es va manifestar sobretot a les grans urbs, però la falta d' estudis quantitatius i la falta de documentació ens impedeixen donar dades estadístiques (Smet, O. Carm. 1991: 313). Encara que la impressió d'obres manuals com Espejo Carmelitano del terciari José Zaragoza i Parada escrita en 1742, de la qual es van arribar a fer fins a tres edicions, és una mostra del seu apogeu (Smet, O. Carm. 1991: 251-256)

\section{Roque Alberto Faci i el seu Carmelo Esmaltado}

Carmelo Esmaltado con tantas brillantes estrelles, cuantas flores terceras, fecundas de frutos de virtud y religión, cultivó y fijó en el cielo de la Santa Iglesia la venerable Orden Tercera de Nuestra Señora del Carmen, és el títol de la obra que Roque Alberto Faci (1684-1744) va publicar al $1743 .^{5}$ L'autor, carmelita de l'antiga observança, posseeix gairebé quaranta obres impreses en què mostra la seva immensa tasca historiogràfica i apologètica sobre el Carmel. ${ }^{6}$ També, cal destacar la seva carrera intel lectual, per una banda, estudiant filosofia i teologia dels quals rebé el grau de doctor, i per l'altra, la seva feina com bibliotecari, docent i rector del col legi de san José de Zaragoza, la ocupació com a prior del convent d'Alcanyís i examinador sinodal del bisbat d'Albarracín (Gómez Uriel 1886: 294).

En vista de les dades que tenim, situarem al polígraf i la seva obra considerant les seves afinitats culturals. Durant la primera meitat del segle XVIII, les tendències barroques quedaren arcaiques i la desmesurada influència de la literatura espiritual havia d'enfrontar-se a la maduresa teològica que oferí la Il lustració Catòlica. Tot i això, trobem que les cròniques de la majoria de les ordres es van escriure a començament del segle XVIII i foren dirigides a una societat saturada de religiositat, exhausta per una profunda crisi econòmica, amb una dinastia nova, de la qual s'ignorava el seu grau de compromís religiós, i el naixement d'una nova manera de pensar que prioritzava la raó a la fe

5 Data de l'aprovació.

6 Actualment ens trobem treballant la biografia i bibliografia del personatge a la tesis doctoral de l'autor de l'article.

SCRIPTA, Revista internacional de literatura i cultura medieval i moderna, núm. 8 / desembre 2016 / pp. 241-256 ISSN: 2340-4841 · doi:10.7203/SCRIPTA.8.9297 
Cristina Gimeno-Maldonado. Vides exemplars. Terciàries carmelitanes a El Carmelo Esmaltado de Roque Alberto Faci (1743)

(Catalán Martínez 2012 :250). Amb tot, cal mencionar la quantitat de llibres, imatges, prèdiques i una munió de noves formés que varen actuar d'instruments. Aquests recursos procuraren difondre el discurs religiós que impregnà tant les consciències com les voluntats amb preceptes doctrinals. Però sobre tot, establiren els paràmetres d'una pràctica devota, sistemàtica i ordenada, mitjançant models de vida que s'oferien a imitació, amb pautes sobre les quals regir el comportament dels subjectes amb les seves relacions amb la divinitat, amb els altres membres de la comunitat i amb l'autoritat eclesiàstica i secular (Palomo 2013: 53-88). Per això, pretenem analitzar els propòsits i estil de l'obra amb molta atenció, ja que s'aprecia el to crític i el rebuig cap a les noves correntes i altres tendències socials, les quals preocuparen a un gran nombre de religiosos aferrats al barroquisme. ${ }^{7}$ Com apunta Federico Palomo (2013: 53-88), no hem d'analitzar els continguts d'ordre moral i doctrinal, sinó posar atenció a les diferents actuacions i contextos en què aquest discurs es feia present en funció del context en què havia de produir-se la comunicació, del objectius que es perseguien i dels públics a què es pretenia arribar.

L'exemplar, que posseeix 599 pàgines, és un tractat per als membres de la tercera ordre del Carmel. Segurament fou articulat per aquells membres de l'orde tercera de Saragossa que existia a la ciutat des de feia pocs anys. ${ }^{8}$ Segons el carmelita Higinio Ganadarias fou «el mejor libro escrito sobre la Tercera Orden hasta el tiempo que estamos escribiendo» (1954) (Smet, O. Carm. 1991: 163).

L'obra està dividida en quatre llibres. El primer, Del origen, aprobación, antigüedad, progresos y votos de la Venerable Tercera Orden de Nuestra Señora del Carmen, es compon de set capítols que recullen una compilació històrica i historiogràfica sobre l'origen, l'aprovació i diferents successos constatats. L'autor remunta l'existència a mitjan segle VIII, fent un repàs a l'obra fundacional de Francesc d’Assís i Domingo de Guzmán, fins el segle XVIII. Amb to crític però recorrent a les diferents obres Lezana, diverses butlles papals, diferents annals i relacions de successos que segurament foren rebudes a la seva biblioteca durant anys. Amb tot, Faci denuncia tot allò que intenta desacreditar els privilegis de la tercera ordre, a més d'establir, segons ell, els paràmetres correctes sobre la història de l'ordre, a l'hora que depurar i desacreditar totes les informacions que segurament no li varen semblar apropiades.

A tota l'exposició traspua la voluntat de discussió que existí durant el segle XVIII a l'hora de realitzar una nova història crítica. Totes les explicacions van acompanyades de múltiples cites, referències $\mathrm{i}$ explicacions, en aquests cas, de forma redundant:

Mas: Cherubino solamente trae veinte y cuatro Bules de Sixto IV, pertenecientes a diversos, y nuestro
Monsiguani de soles les expedidas de Sixto IV, a favor de Nuestra Orden, tare cuarenta y una. Véase quién
fue más, o erudito o dichoso en esta materia, Cherubino o nuestra Monsiguani? Mas: Cherubino por ventura
trae todas les bulles de los les religiones? Mas: Cherubino no dice de dónde sacó los trasuntos de las Bules,

7 El terme barroquisme l'utilitzem entenent-lo no com a sinònim de barroc, sinó com la degeneració universal del genuí barroc.

8 Connotació que fa el Dr. Francisco Lorieri al 1743, censor diocesà de l'obra de Faci.

SCRIPTA, Revista internacional de literatura i cultura medieval i moderna, núm. 8 / desembre 2016 / pp. 241-256 ISSN: 2340-4841 · doi:10.7203/SCRIPTA.8.9297 


\begin{abstract}
contentándose con afirmar que vio algunas bibliotecas y citar algunas veces al colector. Pero nuestro Monsignani en todas cita la original o trasuntos autentificados, y donde se halla, en que se ve que fue mayor el cuidado y estudio de nuestro Montiguano acerca de les Bules de nuestra Orden, que el de Cherubino, y a quien importaba más ese estudio (Faci 1743: 25).
\end{abstract}

També es nota la voluntat de Faci per aclarir i establir les diferències entre aquells que pertanyien a l'ordre com terciaris i als confrares, ja que aquests últims no tenien regla per seguir, ni professió, ni vestien l'hàbit. Tan sols tenien certs estatuts de pietat, per tant, no posseïen els mateixos privilegis $\mathrm{i}$ indulgències. Les pretensions de capítol són clares, com ell mateix assenyala «se ingiere este libro para la más legalidad memoria de la justicia que tiene nuestra religión (...) en la Tercera Orden» (Faci 1743:43).

Com es demostra, aquests tipus de cròniques pretenien crear i consolidar la identitat del grup, a través de desenvolupar-ne un sentit bàsic de pertinença. La recreació d'una història col lectiva és una rica plataforma per reforçar la cohesió, desenvolupar una consciència comuna, disciplinar i procurar una activitat militant. Per tant, el llibre posseeix una funció integradora (Atienza López, 2012: 25-50).

El segon llibre, En que se trata de la Regla, està dividit en catorze capítols. Aquí, Faci assumeix totes les explicacions sobre com s'ha d'acomplir la regla de Sant Albert, ${ }^{9}$ que és la que segueixen els terciaris carmelites. La Regla, formada per dotze articles, és el text basic i central de l'espiritualitat carmelitana. És important conèixer la fórmula original per una bona interpretació de la seva espiritualitat. D'aquesta es pot apreciar la paradoxa existencial de la seva essència carmelita: soledat i comunitat, que és d'identitat clau, fins i tot amb les transformacions succeïdes amb el pas dels segles (Duchet-Suchaux, Duchet-Suchaux 1993: 71-74). Quant als terciaris, cal tenir en compte la Formula Vitae: soledat i oració continua, que no pot ser duta a terme amb rigurositat, però que tot i així partien de la premissa d'una espiritualitat senzilla i sense pretensions; així mateix, una sòlida devoció a la Verge Maria.

De tota la compilació d'articles, ens crida l'atenció que quatre fossin orientats únicament cap al públic femení. Aquestes pautes descriuen com complir el retir i l'honestedat, la castedat i la lluita contra l'ociositat. També s'expressa com devien ser duts a terme les pertinents pràctiques, els rituals, la veneració cap als superiors i com aquests últims havien d'exhortar a les membres a visitar esglésies. En aquesta mateixa línia, s'explica el necessari per evitar, corregir o solucionar les tendències d'amor mutu entre les religioses. De nou, queda confirmat el perfil predilecte que tenien cap al públic femení així com la preocupació per orientar les conductes de les dones.

El tercer llibre, De les constituciones de la Venerable Tercera Orden de la Religión de Nuestra Señora del Carmen, està dividit en onze capítols. En els primers es recullen les constitucions basades en els textos d'Straccio, donant-los com a vàlids i reafirmant el rebuig cap a les innovacions posteriors assumides per el generalat. En capítols que segueixen reflecteixen paràmetres múltiples, condiciones

9 El text inicial fou promulgat cap a l'any 1210. 
Cristina Gimeno-Maldonado. Vides exemplars. Terciàries carmelitanes a El Carmelo Esmaltado de Roque Alberto Faci (1743)

i qualitats que s'havien de tenir en compte per acceptar a algú a l'ordre. Requisits com ara ser majors de quaranta anys, de virtut provada, provenir de famílies honrades, o posseir alguna hisenda en condició de dot, entre d'altres. També s'expliquen detalles més protocol laris com eren la manera de vestir l'hàbit, comportar-se durant el noviciat, com professar, com devia ser portat el càrrec de priora, així com els criteris que s'havien de seguir per la seva elecció.

L'últim llibre, el quart, Ofrece a nuestros terceros y terceras por ejemplares de la virtud, a algunos santos y a otras persónas de Nuestra Venerable Tercera Orden, explica molts relats de vides terciàries, d'homes i dones, però també hagiografies d'alguns sants. Són trenta-cinc biografies, vint-i-dues de dones terciàries. Algunes són de vides totalment anònimes, de les quals gairebé no en tenim dades, tampoc cronològiques, d'altres de conegudes dones nobles, i també d'aquelles amb certa fama de santes. Les fonts que Faci va fer servir per crear el relat van ser cròniques de ciutats, obres d'altres carmelites, com Juan Bonet, que també va escriure per l'ús de terciaris com Espejo de Nuestra Tercera Orden o Jardín del Carmelo, cròniques sobre la reforma de l'ordre i biografies ja elaborades per altres religiosos.

En primer lloc ens ocuparem d'aquelles vides de dones piadoses, exemples de virtut que van mantenir el vot de virginitat i que van portar les disciplines més exemplars, encara que mai van professar, ja sigui perquè no van poder, no van voler o perquè van sentir predilecció per la tercera ordre. És el cas de Paula Villafranca (m. 1605), donzella valenciana, deixeble de fr. Juan Sanz, qui va començar la seva biografia. Orfe de pares, s'hauria hagut de casar casar-se, però ja des de ben petita va sentir predilecció per la vida religiosa. Paula va aconseguir que el seu tutor legal pagués mil escuts i la renta del pares per vestir l'hàbit terciari al 1599. Un cas semblant fou el de Isabel Cortés (m.1633), veïna de Medina de Campo i filla de Cristóbal García i Inés Cortes. Tan devota des de petita que amb vuit anys va fer vot de virginitat. La siciliana Ángela de Arena (m.1556) té un relat molt similar, però la seva biografia destaca per ser la millor mestra en virtuts. La vida de l'italiana Rosa Maria Serio (1674-1726) va ser publicada pel jesuïta Josep Gentili el 1738. Filla del facultatiu Antoni Spenati i Francisca Spenati, des de petita es va preocupar per fer una correcta vida espiritual i vestí l'hàbit al 1690, als setze anys. Posteriorment va ingressar a una casa de terciàries on les mateixes germanes van desitjar posar clausura. Aquesta petició va ser aprovada per Inocenci XII el 12 de febrer de 1698. Rosa Maria es convertí en fundadora i priora. Teodora Piquera (1568-1610), veïna de Villa Roya de los Pinares (Aragó) tenia l'obligació de casar-se, però quan va néixer una germana seva va poder fer vot de virginitat i aconseguir portar una vida rigorosa com volia. Sobre Juana Zucala, de la qual en tenim poques dades, s'explica, a partir de l'obra de Pascual Esclapes, Historia de la Ciudad de Valencia (1738), ${ }^{10}$ que fou la fundadora de la casa de Nuestra Señora de la misericordia y les arrepentidas a Valencia.

10 Esclapes tragué la informació d'una butlla de Juli II, promulgada el 25 de novembre de 1551, on es concedí la llicència per fundar la casa.

SCRIPTA, Revista internacional de literatura i cultura medieval i moderna, núm. 8 / desembre 2016 / pp. 241-256 ISSN: 2340-4841 · doi:10.7203/SCRIPTA.8.9297 
Cristina Gimeno-Maldonado. Vides exemplars. Terciàries carmelitanes a El Carmelo Esmaltado de Roque Alberto Faci (1743)

Altres exemples són els d'aquelles dones que, tot i tenir aviat una predilecció per la vida religiosa, van haver de contraure matrimoni per diferents motius. Juana Maria de Quintas, la biografia de la qual escrigué fr. Felipe Ruz, provincial de Castilla, era veïna de Medina de Campo. Filla de camperols, va tenir una infantesa molt piadosa i amb grans desitjos d'ingressar a un convent, però la manca de dot la condicionà i hagué de casar-se.

També hi ha exemples de dones que, tot i no viure sota clausura, van gaudir d'episodis místicoespirituals com una religiosa. El carmelita fr. Francisco García va il lustrar la autobiografia de Isabel de Jesús (1611-1682) fins a convertir-la en una extensa obra. Natural de Toledo, filla de Bles Díez de Ortega i Elena de Sossa i Villaquiran, des de petita va estar plena de favors divins, visions i contactes amb el dimoni. Aquesta biografia té multitud de semblances amb obres dedicades a religioses professes contemporànies a ella, que tant d'èxit van tenir el segle XVI i XVII. I es que són diverses les vides de dones laiques que compleixen amb aquests arquetips de dones que vivien més al món celestial que terrenal (Sánchez-Ortega 2010). És el cas de la veïna de Carlet, Luisa Zaragoza (1647-1726). La seva biografia fou recollida pels canonges Vicente Gregori i Pedro Gil Dolz i impresa al 1728. D'ella se'ns explica que posseïa talents sobrenaturals, que patia múltiples visions i massa contactes amb el dimoni. Encara que va tenir aquests episodis durant tota la seva vida, va contraure matrimoni dues vegades. Sabem que el primer va ser a l'edat de vint anys amb Joseph Hernandorena, bidalgo biscaí, però del segon no en tenim cap dada. Una vegada vídua, va ingressar com a terciària el 1685. El seu relat destaca per la lluita que patia amb els seus sentiments de penediment per haver perdut la seva puresa virginal. La napolitana Maria de Cherubina també va tenir contacte amb el món celestial. A més de ser fundadora del conservatori de Fasano, del qual va ser-ne priora, va haver de patir violents contactes amb el dimoni per ser d'ànima pura, de fet, va passar alguns anys posseïda. Doña María del Águila i Canales (m.1631), filla de la noblesa toledana, té una crònica extensa que es centra en els seus èxtasis, contactes amb dimonis, penitències, turments, dejunis i mortificacions, entre d'altres lamentacions. I un cas molt similar és el de Catalina de Jesús (1559-1612), nascuda a Triana, filla de Luis de Morales i Ana de los Reyes, ollers pobres, que als setze anys es posà l'hàbit i durant la seva vida fou premiada amb diferents visions amb el nen Jesús.

L'exemple de dones dissortades que aconseguien arribar a una vida millor a través de la sortida que l'església proporcionava es corrobora amb el relat de Felipa Trabiessa, una barcelonina que va contraure un matrimoni desafortunat replet de violència domèstica. La seva relació destaca perquè un dia se li va aparèixer la Mare de Déu salvant-la de la mort a mans del seu marit.

També trobem relats d'altres dones en què gairebé no hi apareixen notícies ni altres explicacions. De Maria Bergeda, per exemple, només sabem que va néixer a Vic i que va ser priora i superiora a la seva casa. Una altra catalana va ser Catalina Bovera, veïna d'Olot i de família pobre, que morí a causa de la pesta el 1670. A banda d'aquestes, que podríem considerar anònimes, trobem personatges destacats que ja gaudiren de certa influència. És el cas de doña Catalina Cardona (m. 
Cristina Gimeno-Maldonado. Vides exemplars. Terciàries carmelitanes a El Carmelo Esmaltado de Roque Alberto Faci (1743)

1577), la solitària. ${ }^{11}$ L'autor adverteix que només és resum de les múltiples biografies que s'han escrit sobre l'ermitana que va mantenir relaciones estretes amb Santa Teresa de Jesús. El cas de Maria de Jesús (m.1580), fundadora de Nuestras Carmelitas Descalzas de la Imagen en Alcalá de Henares la vida de la qual va estar publicada a fr. Francisco de Santa María a Crónica de Nuestra Reforma. Filla d'un relator de la chancillería de Granada, inicialment fou novícia, però decidí deixar-lo per formar part de la tercera ordre. Quan enviudà, va vendre la hisenda, viatjà a Roma, consultà amb el pares de Mantua i va tornar a Espanya. A Granada intentà fundar una casa, però no la van deixar. Teresa de Jesús s'assabentà de la seva existència i decidí conèixer-la. Es van reunir a Toledo, a casa de doña Luisa de la Cerda. A partir d'aquella entrevista, Maria de Jesús sortí cap a Madrid on va parlar amb el Nunci. A la Cort va tenir el suport de doña Leonor Mascareñas, que s'oferí a ajudar-la i li cedí unes cases a Alcalà, on ja vivien altres beates. Finalment fundà el convent el 23 de juliol de 1563, onze mesos desprès que Teresa de Jesús comencés la reforma.

Hi ha altres casos de dones que segurament gaudiren de certa fama en vida i que podrien haver assolit el prestigi d'altres dones del mateix segle, però que per diversos motius no ho van aconseguir. És el cas de la mallorquina Eleonor Ortiz. No podem oferir detalls cronològics, ja que, segons Faci, Bonet s'oblidà de posar-hi dates. D'ella s'explica que va passar la infantesa al convent de Santa Margarita i que en va sortir per vestir l'hàbit de la tercera ordre. Parlem d'una dona molt virtuosa que feia escapularis capaços de guarir. El relat es centra en el cas de Cristóbal Ramis, un ric mercader mallorquí que emmalaltí i els metges van deixar per desnonat. El mercader tenia un germà carmelita, fr. Albert Pug, molt aficionat a les virtuts d'Eleanor. Eleanor va donar a fr. Albert Pug un escapulari de la Mare de Déu per tal que el seu germà el portés al coll durant un any. Des del primer moment, Cristóbal va començar a sentir millora i es va acabar guarint. Aquest cas va arribar a les orelles del rei, que ordenà al bisbe de Mallorca que examinés la terciària. Així, la van portar al Palau Episcopal on van confirmar el seu do. Al relat no es donen més dades, ni del rei ni del bisbe.

Sense dubte, la vida més característica és l'escrita pels frares missioners descalços de la congregació italiana, ${ }^{12}$ que Faci segurament va treure de Reforma de los descalzos de Nuestra Señora del Carmen de fray Manuel de san Jerónimo (1706:40-62), historiador i definidor general de la mateixa ordre. És el relat de doña Teresa Sanfhule, comtessa de Sirleyo, nascuda a Circasia, província oriental d'Asia. Aquesta dona, que era neboda del rei persa Abbas, ja de nena va passar molts anys a la Cort perquè l'havien enviat a estudiar. El 1602 va arriba a Haspan (cort de Persia) un ambaixador anglès acompanyat pel seu germà Robert, comte de Sirleyo. Allà es van conèixer, s'enamoraren, i el rei va consentir el matrimoni. Mahometana de religió, el 2 de febrer de 1608 fou batejada a la fe

11 Ometem referències, ja que el personatge té un gran tracte historiogràfic.

12 El 1600 el Papa Clement XIII dividí la nova Ordre del Carmelites Descalços en dos Congregacions: l'Espanyola o de Sant Josep (instaurada a la Península Ibèrica i a les colònies d'ultramar) i la Italiana o de Sant Elies (que tenia al seu càrrec tots el territoris que no pretenien a la monarquia hispànica). De la separació de les dos Congregacions es troba el talant missioner de l'ordre, ja que la Italiana ho assumeix com consubstancial al carisma Teresià, mentre que la espanyola no ho veu així (Fernández de Mendiaola 2002: 156) 
Cristina Gimeno-Maldonado. Vides exemplars. Terciàries carmelitanes a El Carmelo Esmaltado de Roque Alberto Faci (1743)

catòlica per fr. Juan Tadeo, delegat del Papa. Es van casar a la cort persa, però desprès van viatjar per varies corts europees. Com a anècdota, durant aquest viatge van ser assaltats per uns lladres, en el cos a cos Robert va estar a punt de perdre vida, però ella prengué una espasa, matà un del assaltants i es van poder salvar. Arribats a Roma, la comtessa va mantenir relació amb Beatriu de Jesús, neboda de Santa Teresa, de la qual rebé un tros del cor de la Santa. El 1624 el matrimoni va tornar a Pèrsia, però com que el rei havia mort i ningú reconeixia el permís del monarca per canviar de fe, la comtessa fou acusada d'heretge i condemnada a ser torturada i cremada. Van fugir a una casa allunyada de la família de la comtessa, on va morir Robert. Posteriorment, Teresa va aconseguir tornar a Roma emparada per Urbà VIII amb l'objectiu de professar com a religiosa. Els desitjos d'ingressar no es compliren, ja que el Senyor li va encomanar ser exemple de seglars. Quan va prendre l'hàbit de terciària al convent dels pares descalços de l'Escala (Roma) durant trenta-cinc anys. Finalment morí el 1668 amb setanta-nou anys.

Aquest últim capítol podria catalogar-ne com a pertinent al gènere de l'hagiografia, però en concret al sub-gènere de les cartes edificants, enteses com un compendi de virtuts de certa persona escrites poc després de la seva mort. Així, partim de dues inferències, en primer lloc, la de considerar l'obra dins del gènere de l'hagiografia, que tingué gran èxit durant el barroc, per abastir a la creixent demanda de vides de sants i episodis meravellosos i taumatúrgics, i en segon lloc, per l'apropiació del gènere que realitzaren les ordres religioses, en rivalitat constant entre elles, pretenent acumular a les seves files més i millors sants. Però aquestes cròniques no sols es van pensar com a instruments de propaganda de l'ordre de cara l'exterior, sinó que també van tenir una gran importància davant del consum i enfortiment intern dels integrants, alguns d'ells no arribats amb vocació prèvia, precisa i clara. És per això que aquest tipus d'obres també procuraven la cohesió, la disciplina i la militància (Atienza López 2012: 41).

Considerant aquestes qüestions, trobem que aquesta literatura va tenir un paper important en els procés disciplinari, en la mesura en què ajudaven a modelar comportaments, ja que el discurs havia d'orientar la consciència i la voluntat de les dones. I que, al marge de proposar-ne models de vida i comportaments, va existir la funció de reflectir les virtuts de la pròpia ordre, pel consum intern i extern, oferint aquests relats en el si d'una cultura molt marcada per dues nocions de distinció, l’honor i la honradesa (Atienza López 2013: 89-105).

\section{Conclusions}

El segle XVIII és considerat una clara expressió del canvi. Pel que fa a l'espiritualitat, l'auge del catolicisme il lustrat davant les postures conservadores demostrà el dinamisme que respirava el catolicisme durant segles. Davant les transformacions progressives, l'Església sempre procurà establir noves pautes de comportament per reconduir el poble segons els seus interessos. En aquesta ocasió, trobem un segle de simplicitat popular respecte el culte a les relíquies, els pensaments doctrinals, 
Cristina Gimeno-Maldonado. Vides exemplars. Terciàries carmelitanes a El Carmelo Esmaltado de Roque Alberto Faci (1743)

l'exteriorització de formes religioses, etcètera. No per això però, en el cas ibèric, descristianitzat. L'àmbit clerical i el fervor religiós, per exemple, va deixar de mirar cap els altars, va sortir del convent i va mirar cap als carrers, les processons i tradicions portades a terme pel poble. En aquest context, les branques terciàries adquiriren un paper important com actors religiosos mitjançant la seva participació en actes públics de cohesió i devoció. Alhora, també oferien una nova forma de viure l'espiritualitat a partir de la sociabilitat de laics al marge d'arcaiques formes poc pràctiques en la vida a l'ús.

En aquest marc trobem Carmelo Esmaltado, obra dedicada al funcionament i organització de la tercera branca de l'ordre del Carmelo, abraçant fundació, organització i desenvolupament. Podem catalogar l'obra com un manual amb finalitats pràctiques i pedagògiques orientada al lector terciari, però amb característiques de control i exuberància, en part amb finalitats conservadores. Rebutja sistemàticament les noves corrents culturals premiant tots aquells trets que guarden similitud amb les expressions religioses vívides durant el Segle d'Or. En la mateixa línia, no hem de menystenir la funció de cohesió que tenien aquest tipus de tractats per als membres de l'ordre. Per tant, també posseeix funciones de prevenció i reticència que demostren la pugna de sensibilitats viscudes al segle XVIII entre els arrelats al barroc i els novators il lustrats.

Amb tot, cal destacar la importància que Faci va atorgar a les biografies. A pesar de trobar algun relat masculí, la intenció de retratar vides femenines és molt superior. Aquest fenomen cal entendre'l des de dos vessants; En primer lloc, cal destacar que l'Ordre del Carmen sempre va prioritzar, a partir de Santa Teresa, la dedicació a les dones. De fet, des de la reformadora, la participació de dones a l'ordre, ja fossin beates o religioses, va créixer ininterrompudament. En segon lloc, destaquem la preocupació per part de tractadistes i moralistes, entre els quals incloem a Roque Alberto Faci, per oferir exemples virtuosos amb finalitats moralitzants. Aquest tipus de col lectius i associacions religioses es convertí en una sortida per a moltes dones, per això, el discurs cap a elles dins d'aquests grups procurà, mitjançant prescripcions de conductes, establir uns determinats models de conducta preexistents. Aquests arquetips designats a la dona varen fer-ne un subjecte passiu a la història, no pensador, si no ja pensat (per homes) i obligada a trobar-se a si mateixa en un model. Així, cada exemple de vida aporta un model a seguir, oferint múltiples variants i particularitats, agents que provocaren que qualsevol dona de l'època pogués sentir-se identificada amb alguna d'elles. En conclusió, oferint sempre la identificació genèrica, la imitació i un rol ja determinat. 
Cristina Gimeno-Maldonado. Vides exemplars. Terciàries carmelitanes a El Carmelo Esmaltado de Roque Alberto Faci (1743)

\section{Bibliografia}

Aguilar Piñal, F. - Domínguez Ortiz, A. (1976) Historia de Sevilla IV: El barroco y la Ilustración, Sevilla, Universidad de Sevilla

Alabrús Iglesias, R.M. - García Cárcel, R. (2015) Teresa de Jesús. La construcción de la santidad femenina, Madrid, Cátedra

Ancilli, E. (1984) Diccionario de espiritualidad II, Cádiz, Universidad de Cádiz

Antón Solé, P. (1994) La Iglesia gaditana en el siglo XVIII, Cádiz, Universidad de Cádiz

Atienza López, A. (ed.) (2012) Iglesia memorable. Crónicas, historias, escritos... A mayor gloria. Siglos XVIXVII,. Madrid, Silex

- (2012) «Las crónicas de las ordenes religiosas en la España moderna. Construcciones culturales y militantes de época barroca» dins Atienza López, A. (ed.) Iglesia memorable. Crónicas, historias, escritos... A mayor gloria. Siglos XVI-XVIII. Madrid, Silex, 25-50

- - (2013) «El mundo de las monjas y los claustros femeninos en la edad moderna. Perspectivas recientes y algunos retos» dins Serrano, E. (ed.) De la tierra al cielo. Lineas recientes de investigación en historia moderna, Zaragoza, Institución Fernando el Católico, 89-105

Burrieza Sánchez, J. (ed.) (2015) El alma de las mujeres. Ámbitos de espiritualidad femenina en la modernidad (siglos XVI-XVIII), Valladolid, Universidad de Valladolid

Catalán Martínez, E. (2012) «La aventura de fundar. La versión heroica de las crónicas religiosas» dins Atienza López, A. (ed.) Iglesia memorable. Crónicas, historias, escritos... A mayor gloria. Siglos XVIXVIII, Madrid, Silex, 231-250

Cuartero Arina, R. (2013) Tesis doctoral: Mujeres transgresoras: el delito sexual en la Zaragoza de los siglos XVI y XVII, Universidad de Zaragoza

De la Hera Pérez-Cuesta, A. (2014) «El regalismo borbónico» dins Escudero J.A. (ed.) La Iglesia en la historia de España, Madrid, Fundación Rafael del Pino, 645-659

De la Vega del Carmen, E. (1969) «Espiritualidad barroca e ilustrada» dins Jiménez Duque, B.- Sala Balust, L. (eds.), Historia de la espiritualidad II, Barcelona, Juan Flors Jiménez

Fernández de Mendiaola, D.A. (2002) «Opción Misional de la Congregación Italiana siguiendo el espíritu de Santa Teresa y la llamada de los Papas», Monte Carmelo, 110

Duchet-Suchaux, G. - Duchet-Suchaux, M. (1993) Les ordres religieux, Paris, Flammorin

Escudero J.A. (ed.)2014: La Iglesia en la historia de España, Madrid, Fundación Rafael del Pino

Faci, R.A. (1743) Carmelo Esmaltado con tantas brillantes estrellas, cuantas flores terceras, fecundas de frutos de virtud y religión, cultivó y fijó en el cielo de la Santa Iglesia la venerable Orden Tercera de Nuestra Señora del Carmen. Zaragoza, Imprenta de Francisco Moreno

- (1767) Instrucción necesaria para saber el valor y preciosidad del santo escapulario de Nuestra Señora del

SCRIPTA, Revista internacional de literatura i cultura medieval i moderna, núm. 8 / desembre 2016 / pp. 241-256 
Cristina Gimeno-Maldonado. Vides exemplars. Terciàries carmelitanes a El Carmelo Esmaltado de Roque Alberto Faci (1743)

Carmen: Dividida en cuestiones, Zaragoza, Imprenta de Francisco Moreno

García-Villoslada, R. (dir.) (1979) Historia de la Iglesia de España, Madrid, BAC

Gómez Uriel, M. (1886) Bibliotecas antigua y nueva de escritores aragoneses de Latassa aumentadas y refundidas en forma de diccionario bibliográfico-biográfico, Zaragoza, Imprenta de Calixto Ariño

Jedin, H. (ed.) (1978) Manual de historia de la Iglesia VI, Barcelona, Herder

Jiménez Duque, B.- Sala Balust, L. (eds.), Historia de la espiritualidad II, Barcelona, Juan Flors Jiménez

López-Cordón Cortezo, M.V. (2015) «Los estudios históricos sobre las mujeres en la Edad Moderna: estado de la cuestión». Revista de historiografía 22, 147-181

Martínez Albiach, A. (1969) Religiosidad hispana y sociedad borbónica. Burgos, Facultad teológica del norte de España

Mestre Sanchís, A. (1979) «Religión y cultura en el siglo XVIII» dins García-Villoslada, R. (dir.): Historia de la Iglesia de España, Madrid, BAC

Palomo, F. (2013) «Cultura religiosa, comunicación y escritura en el mundo ibérico de la edad moderna» dins Serrano, E. (ed.) De la tierra al cielo. Lineas recientes de investigación en historia moderna. Zaragoza, Institución Fernando el Católico

Po-Chi Hsia, R. (2010) El mundo de la renovación católica, 1540-1770, Madrid, Akal

Raab, H. (1978) «Fin de la era confesional en Europa» dins Jedin, H. (ed.), Manual de historia de la Iglesia VI, Barcelona, Herder

San Jerónimo, M. (1706) Reforma de los descalzos de nuestra orden del Carmen de la primitiva observancia hecha por santa Teresa de Jesús $V$, Madrid, Jerónimo de Estrada

Sánchez-Ortega, M.H. (2010) Escritoras religiosas españolas. Trance y literatura (siglos XV-XIX), Edición Digital: El Cid editor

Serrano, E. (ed.) (2013) De la tierra al cielo. Lineas recientes de investigación en historia moderna. Zaragoza, Institución Fernando el Católico

Smet, J., O. Carm. (1991), Los carmelitas III, Madrid, BAC

Torremocha Hernández, M. (2015) «Modelos de espiritualidad barroca» dins Burrieza Sánchez, J. (ed.) El alma de las mujeres. Ámbitos de espiritualidad femenina en la modernidad (siglos XVI-XVIII), Valladolid, Universidad de Valladolid

Velasco, B. O.Carm. (1993) Los carmelitas IV, Madrid, BAC

Vigil, M. (1986) La vida de las mujeres en los siglos XVI y XVII, Madrid, Siglo XXI

Wilderink, V. (1966) Les constitutions des premiers Carmélites en France, Roma, Institutum Carmelitanum

SCRIPTA, Revista internacional de literatura i cultura medieval i moderna, núm. 8 / desembre 2016 / pp. 241-256 